EXTENDED REPORT

\title{
The preoperative intraocular pressure level predicts the amount of underestimated intraocular pressure after LASIK for myopia
}

\author{
E Chihara, H Takahashi, K Okazaki, M Park, M Tanito
}

Br J Ophthalmol 2005;89:160-164. doi: 10.1136/bjo.2004.048074

See end of article for authors' affiliations

.....................

Correspondence to: Etsuo Chihara, MD, PhD, Sensho-kai Eye Institute, Minamiyama $50-1$, Iseda, Uji, Kyoto 611-0043, Japan; chiha49@

sa2.so-net.ne.jp

Accepted for publication 1 August 2004 nce of the parameters that affect underestimation of intraocular Aims: To evaluate the statistical significance of the parameters that
pressure (IOP) after laser in situ keratomileusis (LASIK) for myopia.

Methods: In this prospective case series study, patient age, axial length, preoperative corneal curvature, preoperative central corneal thickness (CCT), preoperative IOP, and ablation depth were studied to determine whether they affect the underestimation of IOP in the right eyes of 100 consecutive patients who underwent LASIK.

Results: The preoperative IOP was the most important parameter for an amount of underestimated Goldmann applanation tonometric IOP (GAT) and non-contact tonometric IOP (nclOP) at 1 month $\left(r=0.654, \mathrm{p}<0.0001, \mathrm{R}^{2}=0.427\right.$, and $r=0.694, \mathrm{p}<0.0001, \mathrm{R}^{2}=0.481$, respectively) and 3 months $\left(r=0.637, \mathrm{p}<0.0001, \mathrm{R}^{2}=0.406\right.$, and $r=0.726, \mathrm{p}<0.0001, \mathrm{R}^{2}=0.527$, respectively). Patient age was statistically significant for underestimating the GAT at 1 month, and both the ablation depth and CCT were statistically significant parameters for underestimating the nclOP at 1 month and at 3 months by stepwise multiple regression analysis $(F>4.000)$. However, these parameters had small bivariate correlation coefficients, and were considered as minor parameters.

Conclusion: Preoperative IOP is the most important parameter that affects an underestimation of IOP after LASIK for myopia. Eyes with a higher true IOP have a larger underestimation of the IOP after LASIK for myopia. From these results, the importance of the modulus of elasticity on IOP measurements was discussed.
$\mathrm{T}$ he assessment of precise intraocular pressure (IOP) is of clinical importance for detecting early glaucoma and evaluating the efficacy of hypotensive treatment in patients with glaucoma and ocular hypertension. If the IOP is underestimated after refractive surgeries, especially those for myopia, clinical problems may ensue. Continuing efforts to estimate the precise IOP is of clinical importance, because myopia is a risk factor for primary open angle glaucoma. Patients with myopia and glaucoma may have rapid deterioration of the visual fields, ${ }^{2}$ and patients affected are at risk for selective impairment of macular function. ${ }^{34}$

Recently, several reports have been published on the underestimation of IOP after various refractive procedures such as radial keratotomy, ${ }^{5}$ photorefractive keratectomy, ${ }^{5} 6$ and laser in situ keratomileusis (LASIK). ${ }^{7}$ The effect of latanoprost may also be underestimated. ${ }^{8}$ Thus, efforts are being made to obtain precise IOP measurements. ${ }^{8-10}$

To obtain precise IOP data subsequent to refractive surgery, studies of various parameters that may impact the underestimation of the IOP are of considerable importance. Parameters that have been evaluated include ablation depth, ${ }^{11}$ age, ${ }^{5}$ preoperative IOP, ${ }^{11}$ interstitial tissue fluid, ${ }^{12}$ decreased corneal resistance to applanation, ${ }^{13}$ and corneal curvature. ${ }^{14}$

In normal eyes there is a positive correlation between corneal thickness and IOP. ${ }^{15}$ Thus, it may be reasonable to expect a positive correlation between the ablation depth and the amount of underestimated IOP. However, the reported findings on this putative correlation after LASIK are controversial. While several authors have reported a significantly positive correlation, ${ }^{611} 16$ others have not. ${ }^{51317}$ Furthermore, in some reports, underestimation of the IOP occurs after radial keratotomy, in which there is no tissue loss, ${ }^{5}$ or after LASIK for hyperopia, in which central corneal ablation is minimal. ${ }^{17}$
It may well turn out that the cause of underestimation of the IOP after LASIK is multifactorial, and thus a multivariate analysis would be more appropriate to assess the importance of contributing parameters.

\section{PATIENTS AND METHODS \\ Patients}

Clinical data were obtained prospectively from the right eyes of 100 consecutive patients who underwent LASIK for myopia between April 2001 and April 2002 at Sensho-kai Eye Institute. The patients included in the study were healthy myopic subjects who were scheduled for LASIK treatment and had no systemic or ocular diseases other than myopia. All patients were treated according to the institutional treatment protocol. Patients with a cornea of less than $480 \mu \mathrm{m}$ thickness, active anterior segment diseases, a history of ocular surgery, glaucomatous optic neuropathy, IOP greater than $21 \mathrm{~mm} \mathrm{Hg}$ as determined by a Goldmann applanation tonometer, dry eye, a known history of trauma, undergoing treatment with topical or systemic steroid therapy, those who do not adhere to the follow up protocol, and those who underwent re-treatment during follow up, were excluded. Based on these exclusion criteria, data from seven patients were excluded, and the ultimate statistical analysis was based on the data from 93 eyes in 93 patients. Informed consent was obtained from all patients before LASIK, and all procedures followed the tenets of the 1989 Declaration of Helsinki.

Abbreviations: CCT, central corneal thickness; GAT, Goldmann applanation tonometric IOP; IOP, intraocular pressure; IOPT, true IOP; LASIK, laser in situ keratomileusis; ncIOP, non-contact tonometric IOP 
Table 1 Time course of the CCT, refractive error, and IOP (mean (SD))

\begin{tabular}{llll}
\hline & $\begin{array}{l}\mathbf{1} \text { week } \\
\text { postoperative }\end{array}$ & $\begin{array}{l}\mathbf{1} \text { month } \\
\text { postoperative }\end{array}$ & $\begin{array}{l}\mathbf{3} \text { month } \\
\text { postoperative }\end{array}$ \\
\hline Reduction in CCT ( $\mu \mathrm{m}$ by Orbscan) & $78.9(37.0)$ & $61.5(33.0)$ & $50.3(27.9)$ \\
Improved refractive error (D) & $4.95(2.1)$ & $4.72(1.98)$ & $4.55(1.97)$ \\
Reduction in nclOP $(\mathrm{mm} \mathrm{Hg})$ & $5.1(2.6)$ & $5.1(2.6)$ & $4.8(2.6)$ \\
Reduction in GAT $(\mathrm{mm} \mathrm{Hg})$ & $\mathrm{NA}$ & $2.9(3.1)$ & $3.2(2.8)$ \\
Post-LASIK nc IOP $(\mathrm{mm} \mathrm{Hg})$ & $10.3(2.3)$ & $10.2(2.3)$ & $10.4(2.1)$ \\
Post-LASIK GAT $(\mathrm{mm} \mathrm{Hg})$ & $\mathrm{NA}$ & $13.0(2.5)$ & $12.7(2.5)$ \\
\hline
\end{tabular}

IOP, intraocular pressure; op. LASIK surgery; CCT, central corneal thickness; GAT, Goldmann applanation tonometric intraocular pressure; nclOP, non-contact tonometric intraocular pressure; NA, not applicable.

\section{Methods}

In this prospective case series investigation, the preoperative and postoperative IOP levels were the primary outcome. Before LASIK, uncorrected and best corrected visual acuity, spherical equivalent refractive error, the axial length as determined by A-mode ultrasonography (AL-010, Tomey, Aichi, Japan), endothelial cell count (Noncon ROBO-CA, Konan-Keeler, Kobe, Japan), pupil diameter, the keratometric corneal curvature (RT, Tomey), the central corneal thickness (CCT), and topography as determined by an Orbscan system (Version 3D, Canon-Bausch \& Lomb, Tokyo, Japan), the Goldmann applanation tonometric IOP (GAT), the non-contact (air puff) tonometric IOP (ncIOP) as determined by a Topcon CT90A, Tokyo, tear film break up time, and the size of the palpebral fissure, and the ablation depth, which was defined as a CCT loss displayed on the control panel of the excimer laser (EC5000, Nidek, Aichi, Japan), were all collected in the right eyes of 93 patients. The acoustic factor of the Orbscan system was set at 0.92. Postsurgical data were obtained at 1 week, 1 month, and 3 months after LASIK. Corneal topography and CCT (Orbscan), refractive error, and ncIOP were studied at l week, 1 month, and 3 months after LASIK. Before the LASIK surgery, CCT was examined by both the Orbscan and an ultrasonic pachymeter (AL3000, Tomey). However, the follow up examinations were made by means of a noninvasive Orbscan system out of safety considerations. For Goldmann applanation tonometric examinations, one tonometer, calibrated to within 0.1 degree of error, was employed, and the GAT was measured at 1 and 3 months after LASIK in a special room set aside for LASIK between 5 and 7 o'clock in the evening. Non-contact tonometric IOP was examined by two skilful technicians, both of whom were masked to the type of treatment.

\section{Interventions}

One surgeon (KO) performed all LASIK procedures on both eyes simultaneously. The room temperature was maintained at $20^{\circ} \mathrm{C}\left(\mathrm{SD} 4^{\circ} \mathrm{C}\right)$, and the humidity at $40 \%$ (SD $\left.15 \%\right)$. After topical anaesthesia was induced using 4\% lidocaine (Xylocaine, Astra Zeneca Japan, Osaka, Japan), an $8 \mathrm{~mm}$ corneal flap (160 $\mu \mathrm{m}$ thickness) was created with a microkeratome (M2, Moria, Tokyo, Japan). The corneal parenchyma was ablated with an excimer laser. The optical and transition zones were $5.0-5.5 \mathrm{~mm}$ and $6.0-7.0 \mathrm{~mm}$, respectively.

Topical ofloxacin (5 mg/ml, Santen, Osaka, Japan), and $0.1 \%$ fluorometholone and $0.1 \%$ hyaluronic acid (Santen) were administered postoperatively four times daily for 1 week and 1 month, respectively.

\section{Statistical analysis}

Stepwise multiple regression analysis with a forward selection procedure was used to study the parameters that may affect IOP readings. Parameters with an F value greater than or equal to 4.000 were considered statistically significant

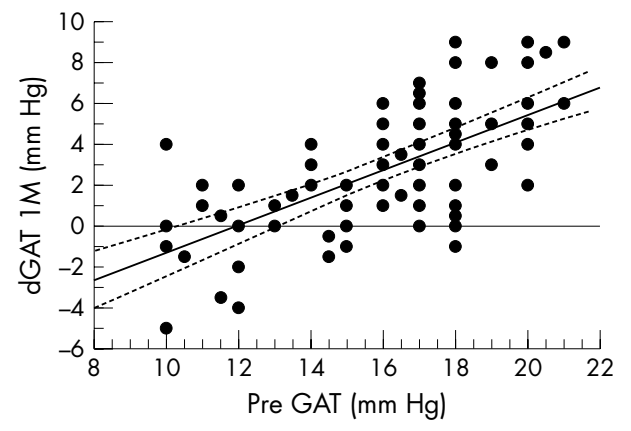

Figure 1 Scatter graph and bivariate regression analysis between the underestimated Goldmann applanation tonometric readings (dGAT = $\triangle$ GAT) 1 month (1M) after LASIK and the preoperative GAT (Pre GAT). The regression line is dGAT $=-8.045+0.677 \times$ pre-GAT, $p<0.0001$, and $R^{2}=0.427$ (95\% confidence bands are shown). Thus, the preoperative GAT level is very important and accounts for $42.7 \%$ of the total underestimation of GAT at 1 month.

(user's guidebook, p 201, Ozaki M, Nankodo, Tokyo 1996). Intercepts and regression coefficients were calculated to obtain the regression equation. The square of the coefficient of multiple determination $\left(R^{2}\right)$ was used to estimate the degree of participation in the underestimation of the IOP.

For bivariate regression analysis, the regression line, 95\% confidence bands, and Pearson's correlation coefficient were calculated. For statistical analysis, Statview v 5.0 software (SAS Institute, Cary, NC, USA) was used.

\section{RESULTS}

The mean (SD) of the preoperative values were as follows: age of the patients ( 51 men, 42 women) 33.2 (8.6) years,

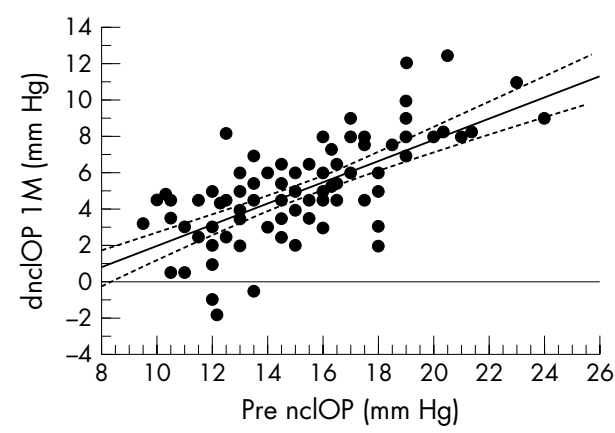

Figure 2 Scatter graph and bivariate regression analysis between the underestimated non-contact tonometric IOP (dnclOP) 1 month (1M) after LASIK and the preoperative ncIOP (Pre ncIOP). The regression line is dnclOP $=-3.99+0.592 \times$ pre $n c l O P, p<0.0001$ and $R^{2}=0.481195 \%$ confidence bands are shown). Thus, the preoperative nclOP level is very important and accounts for $48.1 \%$ of the total underestimation of nclOP at 1 month. 
Table 2 Correlation coefficients between underestimated IOP ( $\triangle$ GAT and $\Delta \mathrm{nclOP}$ ) at 1 month for six parameters

\begin{tabular}{|c|c|c|c|c|c|c|}
\hline & $\begin{array}{l}\text { Correlation coefficient } \\
\text { with } \Delta \text { GAT }\end{array}$ & $95 \% \mathrm{Cl}$ & $\mathrm{p}$ Value & $\begin{array}{l}\text { Correlation coefficient } \\
\text { with } \Delta \text { nclOP }\end{array}$ & $95 \% \mathrm{Cl}$ & p Value \\
\hline Preop GAT & 0.654 & 0.519 to 0.757 & $<0.0001^{*}$ & - & - & $\begin{array}{ll}- \\
-\end{array}$ \\
\hline Preop nclOP & - & - & - & 0.694 & 0.572 to 0.785 & $<0.0001^{*}$ \\
\hline Age & -0.163 & -0.355 to 0.042 & 0.12 & -0.026 & -0.226 to 0.177 & 0.81 \\
\hline Axial length & -0.015 & -0.218 to 0.189 & 0.89 & 0.153 & -0.05 to 0.344 & 0.14 \\
\hline $\begin{array}{l}\text { Preop corneal } \\
\text { curvature }\end{array}$ & 0.036 & -0.169 to 0.238 & 0.73 & -0.018 & -0.219 to 0.184 & 0.86 \\
\hline Preop CCT & 0.075 & -0.131 to 0.274 & 0.48 & 0.053 & -0.151 to 0.252 & 0.61 \\
\hline Ablation depth & -0.072 & -0.272 to 0.134 & 0.49 & 0.191 & -0.011 to 0.378 & 0.063 \\
\hline
\end{tabular}

$\Delta$, difference between preoperative and 1 month postoperative data; $\mathrm{Cl}$, confidence interval; GAT, Goldmann applanation tonometric intraocular pressure; nclOP, non-contact tonometric intraocular pressure; preop, preoperative; CCT, central corneal thickness.

*Statistically significant correlation.

refractive error -5.70 (2.22) dioptres (D), axial length 26.1 (1.02) $\mathrm{mm}$, keratometric reading $7.74(0.25) \mathrm{mm}$, refractive power within a $3 \mathrm{~mm}$ circle 43.2 (1.4) D, CCT by means of Orbscan 529 (32) $\mu \mathrm{m}$, GAT 15.9 (3.0) mm Hg, and ncIOP 15.3 (3.1) $\mathrm{mm} \mathrm{Hg}$. The corneal ablation depth was 66.1 (22.9) $\mu \mathrm{m}$.

The amount of reduced CCT and the improved refractive error in dioptres (D) tend to decline during the follow up period of 3 months (table 1). During the postoperative period, reduction of the IOPs (GAT and ncIOP) and the IOP level were nearly constant (table 1).

On bivariate regression analysis, the correlation coefficient between the $\Delta \mathrm{IOP}$ (with $\Delta$ indicating a difference between the preoperative and postoperative data) at 1 month and the preoperative IOP was significant in both the GAT $(r=0.654$, $\left.\mathrm{p}<0.0001, \mathrm{R}^{2}=0.427\right)$ and ncIOP $(r=0.694, \mathrm{p}<0.0001$, $\mathrm{R}^{2}=0.481$ ) (table 2, figs $\mathrm{l}$ and 2 ). Parameters other than the preoperative IOP - that is, patient age, axial length, preoperative corneal curvature, preoperative CCT, and ablation depth, did not exhibited significant bivariate correlation with $\triangle$ GAT (1 month) or $\Delta$ ncIOP (1 month) (table 2). Bivariate correlation coefficients between $\triangle$ GAT (3 months) or $\Delta$ ncIOP ( 3 months) and six parameters are listed in table 3. Here again, the preoperative IOP exhibited a significant correlation with the $\Delta$ GAT and $\Delta$ ncIOP $(r=0.637, \mathrm{p}<0.0001$, $\mathrm{R}^{2}=0.406$ and $r=0.726, \mathrm{p}<0.0001, \mathrm{R}^{2}=0.527$, respectively). Other than this, only ablation depth $(r=0.242, \mathrm{p}=0.0282$ $\mathrm{R}^{2}=0.059$ ) exhibited a significant correlation with $\Delta$ ncIOP ( 3 months). Parameters other than the preoperative IOP and ablation depth, did not exhibited significant bivariate correlation with $\triangle$ GAT (3 months) or $\Delta$ ncIOP (3 months) (table 3).

The multivariate effects of six independent parameters on the underestimation of IOP at 1 and 3 months were analysed by stepwise multiple regression with a forward selection procedure. When the $\triangle \mathrm{GAT}$ values at 1 month were set as a dependent variable, two of the six parameters were statistically significant based on the stepwise multiple regression analysis $(\mathrm{F}>4.000)$; the preoperative GAT $\left(\mathrm{R}^{2}=0.427\right)$ was the most important, followed by patient age $\left(\mathrm{R}^{2}=0.027\right)$. Thus, $42.7 \%$ and $2.7 \%$ of the underestimation were explainable by the preoperative GAT and patient age, respectively. The regression equation obtained was $\Delta$ GAT $(\mathrm{lM})=-6.079-0.059 \times$ age $+0.678 \times$ preoperative GAT $\left(R^{2}=0.455\right.$ for this equation). When the $\Delta$ ncIOP ( 1 month) was set as a dependent variable for stepwise multiple regression, three of the six parameters significantly affected the $\Delta$ ncIOP ( 1 month) $(\mathrm{F}>4.000)$. The preoperative ncIOP was the most significant parameter $\left(R^{2}=0.481\right)$, followed by ablation depth $\left(\mathrm{R}^{2}=0.037\right)$ and preoperative CCT $\left(R^{2}=0.003\right)$. The regression equation obtained was $\Delta$ ncIOP $(1 \mathrm{M})=3.063+0.628 \times$ preoperative $\operatorname{ncIOP}-0.017 \times$ preoperative CCT $+0.021 \times$ ablation depth $\left(R^{2}=0.535\right.$ for this equation). Neither axial length nor preoperative corneal curvature was a significant parameter in either analysis.

Bivariate correlations between the $\triangle \mathrm{GAT}$ ( l month) and age $(r=-0.163, \mathrm{p}=0.12$, fig 3$)$, that between the $\Delta$ ncIOP ( 1 month) and the ablation depth $(r=0.191, \mathrm{p}=0.063$ : fig 4$)$, and that between the $\Delta$ ncIOP ( 1 month) and the preoperative CCT $(r=0.053, \mathrm{p}=0.61$, fig 5$)$ were not significant despite the positive correlations by multivariate analysis (table 2).

When the $\triangle \mathrm{GAT}$ and $\Delta \mathrm{ncIOP}$ at 3 months were set as the dependent variables for stepwise multiple regression, only the preoperative IOP was a significant parameter for the $\Delta$ GAT $(3$ months). $\Delta$ GAT $(3 \mathrm{M})=-6.455+0.596 \times$ pre GAT $\left(\mathrm{R}^{2}=0.406\right)$. At the same time, three parameters, which were the same as the three important parameters for $\Delta$ ncIOP (1 month), were found to be significant parameters for the $\Delta$ ncIOP $(3$ months $) . \Delta$ ncIOP $(3 \mathrm{M})=3.501+0.638 \times$ preoperative ncIOP $+0.028 \times$ ablation depth $-0.019 \times$ preoperative CCT $\left(\mathrm{R}^{2}=\right.$ 0.615 for this equation).

Table 3 Correlation coefficients between underestimated IOP ( $\triangle$ GAT and $\Delta$ ncIOP) at 3 months for six parameters

\begin{tabular}{|c|c|c|c|c|c|c|}
\hline & $\begin{array}{l}\triangle G A T \text { (correlation } \\
\text { coefficientt) }\end{array}$ & $95 \% \mathrm{Cl}$ & p Value & $\begin{array}{l}\Delta \text { InclOP (correlation } \\
\text { coefficient) }\end{array}$ & $95 \% \mathrm{Cl}$ & $p$ Value \\
\hline Preop GAT & 0.637 & 0.478 to 0.756 & $<0.0001^{*}$ & - & - & - \\
\hline Preop nclOP & - & - & - & 0.726 & 0.604 to 0.814 & $<0.0001^{*}$ \\
\hline Age & -0.095 & -0.317 to 0.137 & 0.423 & 0.012 & -0.206 to 0.228 & 0.918 \\
\hline Axial length & -0.024 & -0.251 to 0.205 & 0.838 & 0.219 & -0.002 to 0.417 & 0.058 \\
\hline $\begin{array}{l}\text { Preop corneal } \\
\text { curvature. }\end{array}$ & 0.130 & -0.102 to 0.348 & 0.272 & 0.008 & -0.21 to 0.209 & 0.946 \\
\hline Preop CCT & -0.001 & -0.229 to 0.228 & 0.996 & -0.008 & -0.225 to 0.209 & 0.94 \\
\hline Ablation depth & -0.105 & -0.325 to 0.127 & 0.377 & 0.242 & 0.026 to 0.436 & $0.0282^{*}$ \\
\hline
\end{tabular}

$\Delta$, difference between the preoperative and the 3 month postoperative data; Cl, confidence interval; GAT, Goldmann applanation tonometric intraocular pressure; nclOP, non-contact tonometric intraocular pressure; CCT, central corneal thickness.

Pearson's correlation coefficient.

*Statistically significant correlation. 


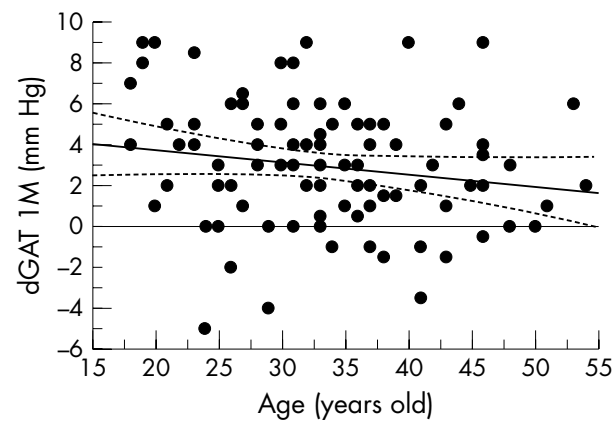

Figure 3 Scatter graph and bivariate regression analysis between the underestimated GAT (dGAT) 1 month (1M) after LASIK and patient age. Age is a significant parameter by stepwise multiple regression analysis $(\mathrm{F}>4.000)$; however, it is not significant by single regression analysis $(r=-0.163, p=0.12)$. This finding suggests that the age is a parameter of minor importance.

\section{DISCUSSION}

For a follow up study of the CCT, an Orbscan system, in which we set an acoustic factor of 0.92 , was used in this study because of its non-invasive character, to protect against damage to the corneal flap. The Orbscan system has highly reproducible data ${ }^{18}{ }^{19}$; however, the corneal thickness or standard deviation obtained with this system may be greater than that obtained with an ultrasonic pachymeter. ${ }^{18}{ }^{20}$ To avoid problems with the Orbscan, we used the ablation depth data displayed on the control panel of the EC5000 for statistical analysis.

From a theoretical point of view, the positive correlation between corneal thickness and the IOP readings ${ }^{15}$ may explain the positive correlation between ablation depth and the reduced IOP reading. ${ }^{611}{ }^{16}{ }^{21-25}$ However, corneal ablation by the refractive surgery is lenticularly shaped and not uniform. This may be one of the reasons for the poor correlation between the ablation depth and reduced IOP reading in our study and in the studies of others. ${ }^{5} 713172627$ Wound healing processes may cause time dependent loss of initially positive correlation between the ablation depth and the reduced IOP reading. ${ }^{24}$

There is clinical evidence that casts doubt on the positive correlation between the post-LASIK ablation depth and the underestimation of IOP. Firstly, the amount of underestimated IOP after LASIK for hyperopia was similar to that after LASIK for myopia. ${ }^{17} 28$ Thus, differences in ablation

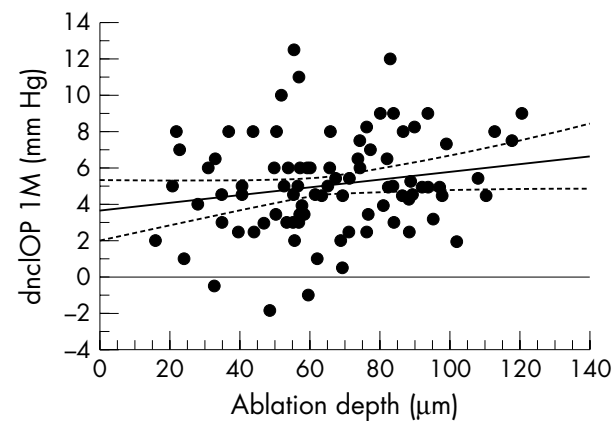

Figure 4 Scatter graph and bivariate regression analysis between the underestimated non-contact tonometric IOP (dnclOP $=\Delta$ nclOP) 1 month (1M) after LASIK and the ablation depth. The ablation depth is a significant parameter by stepwise multiple regression analysis ( $F>4.000)$; however, it is marginally significant by single regression analysis $(r=0.191, p=0.063$, dnclOP $=3.649+0.022 \times$ ablation depth). This finding suggests that the ablation depth is not ignorable, nevertheless it is a parameter of minor importance. depth at the central or the peripheral cornea were not reflected in differences in the amount of the underestimated IOP. Secondly, the IOP measured at the peripheral cornea, where the corneal parenchyma was not ablated after LASIK for myopia, was not free of underestimation, even though the underestimation at the peripheral cornea was milder than at the centre. ${ }^{24}$ Finally, underestimation of the IOP was found after radial keratotomy, in which procedure the corneal parenchyma is not ablated. ${ }^{5}$ A poor correlation between the ablated depth and reduced IOP measurement in this study and the clinical evidence mentioned above suggest that the ablation depth per se may not be the principal cause of IOP underestimation after refractive surgery.

According to a report by Goldmann and Schmidt, the IOP reading can be affected by corneal thickness, ocular rigidity, tear film, and corneal curvature. ${ }^{29}$ Because the changes in corneal curvature after LASIK are correlated closely with the ablation depth, the first three factors may be the main parameters that affect the IOP measurement after LASIK.

In our study, the ablation depth was able to account for only $3.7 \%$ or $5.9 \%$ of the total underestimation of the ncIOP at 1 month or 3 months, and this is of far less importance than the preoperative ncIOP, which was able to account for $48.1 \%$ and $52.7 \%$ of the total underestimation at 1 month and 3 months, respectively. The effect of the preoperative IOP on the underestimation of IOP was reported previously, ${ }^{11}$ and our results confirmed the earlier findings. According to Orssengo and Pye, ${ }^{30}$ the modulus of elasticity (E) is a function of the true IOP (IOPT), and those authors formulated the equation $\mathrm{E}=0.0229 \mathrm{IOPT}$ in the normal eye; thus, eyes with a higher IOPT have a higher E. Purslow and Karwatowski reported an equation of ${ }^{31}$

$$
\left(\frac{d P}{d V}=\frac{t}{\pi} \times \frac{E}{R^{4}}\right)
$$

Thus, E can affect dP. As the collagen fibrils are cut after refractive surgery and cut collagen fibres do not have tensile force, refractive surgery can lead to reduced corneal rigidity. ${ }^{32}$ While the $\mathrm{E}$ is greater in eyes with higher IOPT, the absolute reduction of $\mathrm{E}$ may be greater in eyes with a higher IOPT when the percentage of cut collagen fibres in the cornea is nearly constant.

At a minimum, the reduced modulus of elasticity can help explain the reduced IOP reading at the central cornea after LASIK for hyperopia or radial keratotomy and the reduced

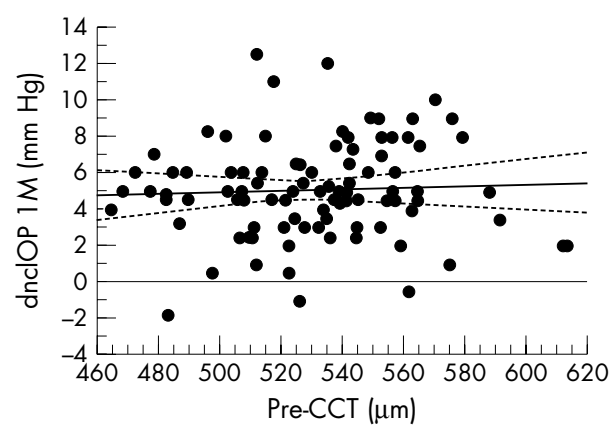

Figure 5 Scatter graph and bivariate regression analysis between the underestimated non-contact tonometric IOP (dnclOP) and the preoperative CCT (Pre-CCT). The preoperative CCT is a significant parameter by stepwise multiple regression analysis ( $F>4.000$ ); however, it is not significant by single regression analysis $(r=0.053, p=0.61)$. Here again, it is suggested that the preoperative CCT is a parameter of minor importance. 
IOP reading at the peripheral cornea where changes of the corneal curvature and corneal thickness are minimal after LASIK for myopia. If the ablation depth is greater after LASIK, the number of cut collagen fibres increases and results in a reduction in $\mathrm{E}$, which in turn results in a more significant underestimation of the IOP unrelated to the ablation depth.

In previous reports, other factors that may affect underestimation of the IOP include preoperative corneal curvature, ${ }^{14}$ changes in corneal curvature, ${ }^{1625}$ age and sex, ${ }^{5}$ and interface fluid. ${ }^{12}$ Corneal ablation can bring about changes in the corneal curvature, and the corneal curvature can in turn affect the IOP measurement, ${ }^{33}$ which may explain the positive correlation between the corneal curvature and $\Delta \mathrm{IOP} .{ }^{16}{ }^{25}$ However, another explanation may be a proportional reduction of the corneal thickness and the consequently reduced $\mathrm{E}$ brought about by the cutting of the collagen fibres.

In our findings, age was determined to be a significant parameter by multivariate analysis, a finding that agrees with that of Faucher and others. ${ }^{5}$ Another study has also reported increased corneal rigidity in elderly subjects. ${ }^{34}$ Increased $\mathrm{E}$ in elderly subjects and differences in the architecture of the collagen fibres ${ }^{35}$ or weak corneal collagen fibres in females may affect the amount of underestimation of the IOP after LASIK. $^{5}$ The increased thickness of the corneal epithelium ${ }^{36}$ may also affect the $\mathrm{E}$ of the total cornea and the IOP measurement after refractive surgery. Studies of these minor parameters of more subtle effect require necessarily larger sample sizes and will be a subject for future analysis.

Tear film, the last of the four parameters reported by Goldmann and Schmidt, ${ }^{29}$ may also affect IOP readings. Dry eye is a common finding after LASIK. ${ }^{37}$ Reduced tear film may increase capillary pressure, which may cause the IOP to be underestimated.

In conclusion, we studied the effect of six parameters on underestimation of the IOP after LASIK for myopia by stepwise multiple regression analysis. Among the six, the preoperative IOP level was the most important parameter, and was able to account for $42.7 \%$ to $40.6 \%$ and $48.1 \%$ to $52.7 \%$, respectively, of the postoperative underestimation of the GAT and ncIOP at 1 month and 3 months. Patients with a higher IOPT have greater underestimation of the IOP. This finding is important for the proper diagnosis and evaluation of treatment outcome in patients with post-LASIK glaucoma.

\section{ACKNOWLEDGEMENTS}

Part of this work as been presented as a poster at the ARVO meeting in 2002 and 2003 at Fort Lauderdale, FL, USA.

The authors have no proprietary interest in any materials that appear in this paper.

\section{Authors' affiliations \\ E Chihara, H Takahashi, K Okazaki, M Tanito, Sensho-kai Eye Institute, Minamiyama 50-1, Iseda, Uji, Kyoto 611-0043, Japan \\ M Tanito, Department of Biological Responses, Institute for Virus Research, Kyoto University, 53 Shogoin, Kawahara-cho, Sakyo-ku, Kyoto 606-8507, Japan \\ Proprietary interest: None.}

\section{REFERENCES}

1 Perkins ES, Phelps CD. Open angle glaucoma, ocular hypertension, low tension glaucoma and refraction. Arch Ophthalmol 1982;100:1464-7.

2 Chihara E, Liu X, Dong J, et al. Severe myopia as a risk factor for progressive visual field loss in primary open angle glaucoma. Ophthalmologica 1997:211:66-71.

3 Mayama C, Suzuki Y, Araie M, et al. Myopia and advanced-stage openangle glaucoma. Ophthalmology 2002;109:2072-7.

4 Chihara E, Tanihara H. Parameters associated with papillomacular bundle defects in glaucoma. Graefes Arch Clin Exp Ophthalmol 1992;230:51 1-17.
5 Faucher A, Gregoire J, Blondeau P. Accuracy of Goldmann tonometry after refractive surgery. J Cataract Refract Surg 1997;23:832-8.

6 Chatteriee A, Shah S, Bessant DA, et al. Reduction in intraocular pressure after excimer laser photorefractive keratectomy. Correlation with pretreatment myopia. Ophthalmology 1997; 104:355-9.

7 Emara B, Probst LE, Tingey DP, et al. Correlation of intraocular pressure and central corneal thickness in normal myopic eyes and after laser in situ keratomileusis. J Cataract Refract Surg 1998;24:1320-5.

8 Tamburrelli C, Vaiano AS, Salgarello T, et al. Tonometric changes of latanoprost-induced intraocular pressure reduction after photorefractive keratectomy. Invest Ophthalmol Vis Sci 2004;45:846-50.

9 Kaufmann C, Bachmann L, Thiel MA. Intraocular pressure measurements using dynamic contour tonometry after laser in situ keratomileusis. Invest Ophthalmol Vis Sci 2003;44:3790-4.

10 Lee D-H, Seo S, Shin S-C, et al. Accuracy and predictability of the compensatory function of Orbscan II in intraocular pressure measurements after laser in situ keratomileusis. J Cataract Refract Surg 2002;28:259-64.

11 El Danasoury MA, El Maghraby A, Coorpender SJ. Change in intraocular pressure in myopic eyes measured with contact and non-contact tonometers after laser in situ keratomileusis. J Refract Surg 2001;17:97-104.

12 Rehany U, Bersudsky V, Rumelt S. Paradoxical hypotony after laser in situ keratomileusis. J Cataract Refract Surg 2000;26:1823-6.

13 Mardelli PG, Piebenga LW, Whitacre MM, et al. The effect of excimer laser photorefractive keratectomy on intraocular pressure measurements using the Goldmann applanation tonometer. Ophthalmology 1997; 104:945-9.

14 Gimero JA, Munoz LA, Valenzuela LA, et al. Influence of refraction on tonometric readings after photorefractive keratectomy and laser assisted in situ keratomileusis. Cornea 2000;19:512-16.

15 Wolfs RCW, Klaver CCW, Vingerling JR, et al. Distribution of central corneal thickness and its association with intraocular pressure: The Rotterdam study. Am J Ophthalmol 1997;123:767-72.

16 Duch S, Serra A, Castanera J, et al. Tonometry after laser in situ keratomileusis treatment. J Glaucoma 2001;10:261-5.

17 Agudelo LM, Molina CA, Alvarez DL. Changes in intraocular pressure after laser in situ keratomileusis for myopia, hyperopia, and astigmatism. J Refract Surg 2002; 18:472-4.

18 Yaylali V, Kaufman SC, Thompson HW. Corneal thickness measurements with the Orbscan topography system and ultrasonic pachymetry. J Cataract Refract Surg 1997;23:1345-50

19 Lattimore MR, Kaupp S, Schallhorn S, et al. Orbscan pachymetry. Implication of a repeated measures and diurnal variation analysis. Ophthalmology 1999: 106:977-981.

20 Prisant O, Calderon N, Chastang P, et al. Reliability of pachymetric measurements using Orbscan after refractive surgery. Ophthalmology 2003; 110:511-15.

21 Masuda A, Shimizu K, Shoji N, et al. The intraocular pressure following excimer laser photorefractive keratectomy. Jpn J Clin Ophthalmol 1999:53:323-6.

22 Burvenich H, Sallet G, DeClercq J. The correlation between IOP measurement, central corneal thickness and corneal curvature. Bull Soc Belge Ophtalmol 2000;276:23-6.

23 Recep OF, Cagil N, Hasiripi H. Correlation between intraocular pressure and corneal stromal thickness after laser in situ keratomileusis. J Cataract Refract Surg 2000;26:1480-3.

24 Park HJ, Uhm KB, Hong C. Reduction in intraocular pressure after laser in situ keratomileusis. J Cataract Refract Surg 2001;27:303-9.

25 Arimoto A, Shimizu K, Shoji N, et al. Underestimation of intraocular pressure in eyes after laser in situ keratomileusis. Jpn J Ophthalmol 2002;46:645-9.

26 Fournier AV, Podtetenev M, Lemire J, et al. Intraocular pressure change measuring Goldmann tonometry after laser in situ keratomileusis. J Cataract Refract Surg 1998;24:905-10.

27 Zadok D, Tram DB, Twa M, et al. Pneumotonometry versus Goldmann tonometry after laser in situ keratomileusis for myopia. J Cataract Refract Surg 1999;25:1344-8

28 Zadok D, Raifkup F, Landao D, et al. Intraocular pressure after LASIK for hyperopia. Ophthalmology 2002;109:1659-61.

29 Goldmann H, Schmidt TH. Ueber Applanationtonometrie. Ophthalmologica 1957; 134:221-42.

30 Orssengo GJ, Pye DC. Determination of the true intraocular pressure and modulus of elasticity of the human cornea in vivo. Bull Mathemat Biol 1999:61:551-72.

31 Purslow PP, Karwatowski WSS. Ocular elasticity. Is engineering stiffness a more useful characterization parameter than ocular rigidity? Ophthalmology 1996; 103:1686-92.

32 Pinsky PM, Datye DV. Numerical modeling of radial, astigmatic and hexagonal keratotomy. Refract Corneal Surg 1992;8:164-72.

33 Mark HH. Corneal curvature in applanation tonometry. Am J Ophthalmol 1973;76:223-4.

34 Sherrard ES, Novakovic P, Speedwell L. Age-related changes of the corneal endothelium and stroma as seen in vivo specular microscopy. Eye 1987; 1:197-203.

35 Axer $\mathbf{H}$, von Keyserlingk DG, Prescher A. Collagen fibers in linea alba and rectus sheaths.J Surg Res 2001;96:239-45.

36 Erie JC, Patel SV, McLaren JW, et al. Effect of myopic laser in situ keratomileusis on epithelial and stromal thickness. A confocal microscopy study. Ophthalmology 2002;109:1447-52.

37 Battat L, Macri A, Dursun D, et al. Effects of laser in situ keratomileusis on tear production, clearance, and the ocular surface. Ophthalmology $2001 ; 108: 1230-5$. 